\title{
Mnemonic and neuroprotective properties of Sclerocarya birrea root bark decoction on mouse model of monosodium glutamate-induced neurotoxicity involve by its antioxidant activities
}

Renaud Nonmarmbaye ${ }^{1,}{ }^{*}$, Nadège Kouemou ${ }^{2}$, Sidiki Neteydji ${ }^{1}$, Jacqueline Stephanie Kameni Njapdounke ${ }^{1}$, Touo'yem Nkemmo Stéphane Willy ${ }^{1}$ and Elisabeth Ngo Bum ${ }^{1,3}$

${ }^{1}$ Department of Biological Sciences, Faculty of Sciences, University of Ngaoundere, P.O. Box 454, Ngaoundere, Cameroon.

2 Department of Zoology and Animal Physiology, Faculty of Sciences, University of Buea, Cameroon, P.O. Box 63, Buea, Cameroon.

${ }^{3}$ Department of Biological Sciences, Faculty of Science, University of Maroua, P.O. Box 814, Maroua, Cameroon.

GSC Biological and Pharmaceutical Sciences, 2021, 17(01), 193-203

Publication history: Received on 18 September 2021; revised on 21 October 2021; accepted on 23 October 2021

Article DOI: https://doi.org/10.30574/gscbps.2021.17.1.0318

\begin{abstract}
Ethnopharmacological relevance: Sclerocarya birrea (A. Rich.) Hochst. (Anacardiaceae) is a medicinal plant known for the treatment of several diseases such as epilepsy, hypertension, inflammation and memory disorders in Cameroonian folk medicine.
\end{abstract}

Aim of the study: The aim of this work is to evaluate the memory improvement and neuroprotective effects of Sclerocarya birrea aqueous root bark extracts and investigate it antioxidant properties.

Materials and methods: T-maze and the object recognition test in an open field were used for behavioral testing to detect its neuroprotective and memory improvement properties. The DPPH test was used to predict antioxidant activities in vitro. The in vivo antioxidant activities of the aqueous extracts were investigated using the Monosodium glutamate induced oxidative stress and neurotoxicity mouse model. After the behavioral testing, animals were decapitated and the brains were removed for oxidative stress biomarkers determination.

Results: Sclerocarya birrea decreased the preferred arm choice latency and the time spent in the discriminated, in the T-maze. It increased exploration time and recognition index, and decreased the latency to explore the new object B. In addition, Sclerocarya birrea increased the superoxide dismutase and catalase activities, and reduced glutathione level.

Conclusion: These results suggest that Sclerocarya birrea possess neuroprotective and mnemonic activities in mice that might involve by its free radicals scavenging properties

Keywords: Sclerocarya birrea; Antioxidants; Neuroprotection; Memory; Folk medicine

\section{Introduction}

Memory is a combination of neurological processes allowing us to acquire, store and recall past experiences and information [1]. However, multiple aggressions of endogenous or exogenous origin often occurred. Glutamate, the most important excitatory neurotransmitter strongly involved in the higher brain functions, including memory [2]. But it can be toxic to neurons at high concentration [3]. Hassan and collaborators in 2014 observed that monosodium glutamate

\footnotetext{
* Corresponding author: Renaud Nonmarmbaye

Department of Biological Sciences, Faculty of Sciences, University of Ngaoundere, P.O. Box 454, Ngaoundere, Cameroon. 
causes neurotoxicity in rodents such as those observed in Alzheimer's disease [4]. It also causes abnormalities in the neuroendocrine system, neurodegeneration as well as oxidative stress damage in various organs including the brain [5].

Recent studies showed the importance of natural antioxidants, because of their therapeutic properties and their accessibility. Indeed, a large majority of populations uses traditional medicine to solve their health problems [6-8]. Bioactive antioxidant agents in plants are selected to provide the first line of biological defense against oxidative stress. Some studies show that oxidative damage constitutes a mechanism of injury found in many age-related diseases [6-8]. The brain is extremely vulnerable to oxidative stress because it requires a high quantity of oxygen and content high level of polyunsaturated fatty acid susceptible to peroxidation. This result to an accumulation of oxidative damage and can cause neurodegenerative diseases such as Alzheimer's. Natural antioxidant substances from plants have been proposed as an alternative for prevention and treatment of these neurological diseases [8].

Sclerocarya birrea (A. Rich.) Hochst. (Anacardiaceae) is a traditional aromatic plant medicine used to treat neuropathic pain, hypertension, dysentery, epilepsy and inflammation. It has antidiarrheal, anti-inflammatory properties and is also used for asthenia [9-11]. The decoction prepared from the root bark of Sclerocarya birrea has been intensively used by the sudano-sahelian's zone traditional healers to treat epilepsy, anxiety and memory loss [10].

Previous studies performed indicated that the aqueous extracts of Sclerocarya birrea were shown to possess antioxidant and acetylcholiesterase inhibitory properties, and can constitutes a source of natural antioxidant and acetylcholinesterase inhibitor [9]; however, there is a substantial lack of systematic study of Sclerocarya birrea extracts and the involved signaling pharmacological pathway remains less elucidated. Therefore, the T-maze and object recognitions tests were used to examine the possible mnemonic and neuroprotective properties of Sclerocarya birrea in monosodium glutamate-induced neurotoxicity mouse model of Alzheimer disease. Additionally, a relationship between the behavioral properties of Sclerocarya birrea extracts and the oxidative stress biomarkers (catalase, superoxide dismutase, and reduced glutathione and malondialdehyde levels) variations in the tested animals were studied.

\section{Material and methods}

\subsection{Plant material}

The root of Sclerocarya birrea used for the experiments was harvested on 17 April 2020 in Moundou (Logone Occidental - Chad). The area of study did not involve endangered or protected species. The collected species was identified by National Herbarium of Yaoundé (Cameroon), where a voucher was deposited (2748SFR).

\subsection{Preparation of Sclerocarya birrea aqueous extracts}

The root bark of Sclerocarya birrea was ground, and $2.5 \mathrm{~g}$ of the obtained powder was introduced in $100 \mathrm{~mL}$ of distilled water. The obtained mixture was boiled for 20 minutes duration and the supernatant was filtered using Whatman No 1 filter paper. The resulting decoctions were then administered orally to mice in a volume of $10 \mathrm{~mL} / \mathrm{kg}$. The decoctions of Sclerocarya birrea were prepared daily according to Traditional Healer's instructions. In another set of experiment the decoction was concentrated using a rotary vacuum evaporator under reduced pressure at $50^{\circ} \mathrm{C}$, and from this procedure the yield of extraction (37.74\%) was calculated. The stock solution of Sclerocarya birrea extract (decoction, $41 \mathrm{mg} / \mathrm{mL}$ ), were diluted in distilled water, and two less concentration solutions (10.25 and $20.5 \mathrm{mg} / \mathrm{mL})$ were obtained.

\subsection{Determination of the in vitro antioxidants activities}

Free radicals are molecules that can cause damage if their levels become too high in the body; compounds that are able to maintain their concentrations at the non-cytotoxicological cell level are call anti-free radicals [13]. Free radical scavenging capacity of the extracts was tested by DPPH radical scavenging assay as described by Blois [14]. The hydrogen atom donating ability of the plant decoction was determined by the decolorization of methanol solution of 2,2-diphenyl-1-picrylhydrazyl (DPPH). DPPH produces violet/purple color in methanol solution and fades to shade of yellow color in the presence of antioxidants. A solution of $0.1 \mathrm{mM} \mathrm{DPPH}$ in methanol was prepared, and $2.4 \mathrm{~mL}$ of this solution was mixed with $1.6 \mathrm{~mL}$ of extract in methanol at different concentrations $(12.5-150 \mu \mathrm{g} / \mathrm{mL})$. The reaction mixture was vortexed thoroughly and left in the dark at RT for $30 \mathrm{~min}$. The absorbance of the mixture was measured spectrophotometrically at $517 \mathrm{~nm}$ [15]. Vitamin C was used as reference. Percentage of DPPH free radical scavenging activity was calculated by the following equation [16]:

$$
\left.I P(\%)=\left(\left(A_{0}-A_{1}\right) / A_{0}\right)\right) \times 100
$$


Where IP is DPPH radical scavenging activity; $A_{0}$ is the absorbance of the control, and $A_{1}$ is the absorbance of the plant.

\subsection{Chemicals}

Monosodium glutamate was purchased from local market. Vitamin C and the others reagents used for the quantification of brain activity were purchased from Sigma Chemical, USA.

\subsection{Animals}

Adult male Swiss mice weighting 20 - 25 g were obtained from the National Veterinary Laboratory, Garoua, Cameroon, and used throughout these experiments. They were housed in standard Plexiglas cages with food and water ad libitum. The animal house was maintained constantly at $25^{\circ} \mathrm{C}$ on a $12 \mathrm{~h}$ light-dark cycle. The protocols were performed in concordance with the International Guide for the Care and Use of Laboratory Animal (National Institute of Health; publication No. 85-23, revised 1996) and the Cameroon National Ethical Committee, Yaounde (No. FW-IRB00001954). In addition, the protocols for pharmacological studies were also realized in compliance with the recommendations provided in the Animal Research: Reporting of In vivo Experiment (ARRIVE) guidelines published online in PLOS Biology [17], and the general guidelines for experimental research and screening of traditional medicine as promulgated by WHO [18].

\subsection{Behavioral testing for the evaluation of mnemonics properties}

\subsubsection{T- maze test}

The T- maze consists of three arms $(30 \mathrm{~cm} \times 10 \mathrm{~cm} \times 25 \mathrm{~cm})$ : one starting arm, a central corridor and two goal arms perpendicular to the central corridor. Opaque guillotine doors placed at the exit of the departure arm and at the entrance of each of the two goal arms allow to control the access to the different arms of the maze. At the end of each goal arm, there is a food that can facilitate the animal's choice. Rewarded alternation is performed for three days and has three phases: habituation, acquisition and retention. During the habituation phase (day 1), the mice were placed in the starting arm of the maze and 15 seconds later, all the guillotine doors were opened. The animal was then allowed to choose an arrival arm of the apparatus indicating its preference, the arm choice at first is called preferred arm [19]. Mice were familiarized with the maze for 5 minutes. The following parameters were recorded for each mouse: latency to choose an arm, number of entries in the preferred and discriminated arms, time spent in the preferred and discriminated arms, and number of returns to the starting arm. During the acquisition phase (day 2), the maze arm discriminated by the animal was closed. The mouse was placed in the starting arm and left to move to the open arm (preferred arm during habituation). The following parameters were recorded: latency to enter the preferred arm, number of entries into the preferred arm, time spent in the preferred arm and number of returns to the starting arm. The retention phase (day 3) was identical to the habituation phase.

\subsubsection{Object recognition test in the open}

The open field used in these experiments consist of a wooden square box $(40 \times 40 \times 45 \mathrm{~cm})$, and the floor of this apparatus was divided into 16 smaller squares $(10 \times 10 \mathrm{~cm})$ of equal dimensions [20]. Described by Ennaceur and Delacour [21], the object recognition test is based on the natural tendency of rodents to explore a new object more than a familiar one. It involves short-term memory processes and tests short-term recognition memory [22].

This test was performed for 3 days and consisted of three phases: habituation, acquisition and retention. To reduce stress due to neophobia, during habituation (day 1), mice were individually familiarized with the open arena for 5 minutes [23]. During acquisition (day 2), animals were placed in the presence of two identical objects (A+A'). The retention phase (day 3 ) was performed as in the acquisition phase, except one of the objects ( $A^{\prime}$ ) was replaced by a new object (B). The time that mouse explore each objects A and B were recorded and noted tA and tB respectively [24]. The animal is considered to be exploring when it directs its snout towards the object at least $2 \mathrm{~cm}$ away from it. The latency time to discover object $\mathrm{A}$ and $\mathrm{B}$, the number of visits to object $\mathrm{A}$ and $\mathrm{B}$ and the time to explore object $\mathrm{A}$ and $\mathrm{B}$ were recorded during 5 minutes. The percentage of Recognition Index (\%IR) of the new object was defined as the percentage of the exploration time of the new object to the total exploration time of both objects. The larger this index is, the better the memory performance in mice $[25,26]$. The percentage of the new object recognition index is calculated as follow:

$$
\% \mathrm{IR}=(\mathrm{tB} / \mathrm{tB}+\mathrm{tA}) \times 100
$$


2.6.3. Biochemical estimation of MDA and reduced glutathione concentration and SOD and catalase activities in the brain of tested animals

Concentration of MDA and reduced glutathione, SOD and catalase activities in the brain homogenate was quantified as follow: SOD activity was determined by the Oyanagui method [27], catalase (CAT) activity was determined by the method of Aebi [28]. The level of GR was done according to the method of Mizumo and Ohta [29] and the concentration of MDA was determined according to the method described by Nourooz-Zadeh [30].

\subsection{Statistical analysis}

Data are shown as means \pm Standard Error of the Mean (S.E.M.). Statistical analysis of significance was carried out using analysis of variance (ANOVA) followed by Tukey's post hoc multiple comparison tests.

P values less than 0.05 were considered as significant

\section{Results}

\subsection{In vitro antioxidants activities Sclerocarya birrea root bark aqueous extracts}

The DPPH radical scavenging activities Sclerocarya birrea root bark aqueous extracts are presented figure 1 and table 1. Free radical scavenging activity using DPPH as the indicator is a basic antioxidant assay. As shown in figure 1 and Table 1, scavenging activities of is 95.78 . The Sclerocarya birrea root bark aqueous extracts scavenging activity ranging at $89.46 \%$. Moreover, the IC50 were 6.52 and 5.51 respectively for vitamin C and the plan extract.

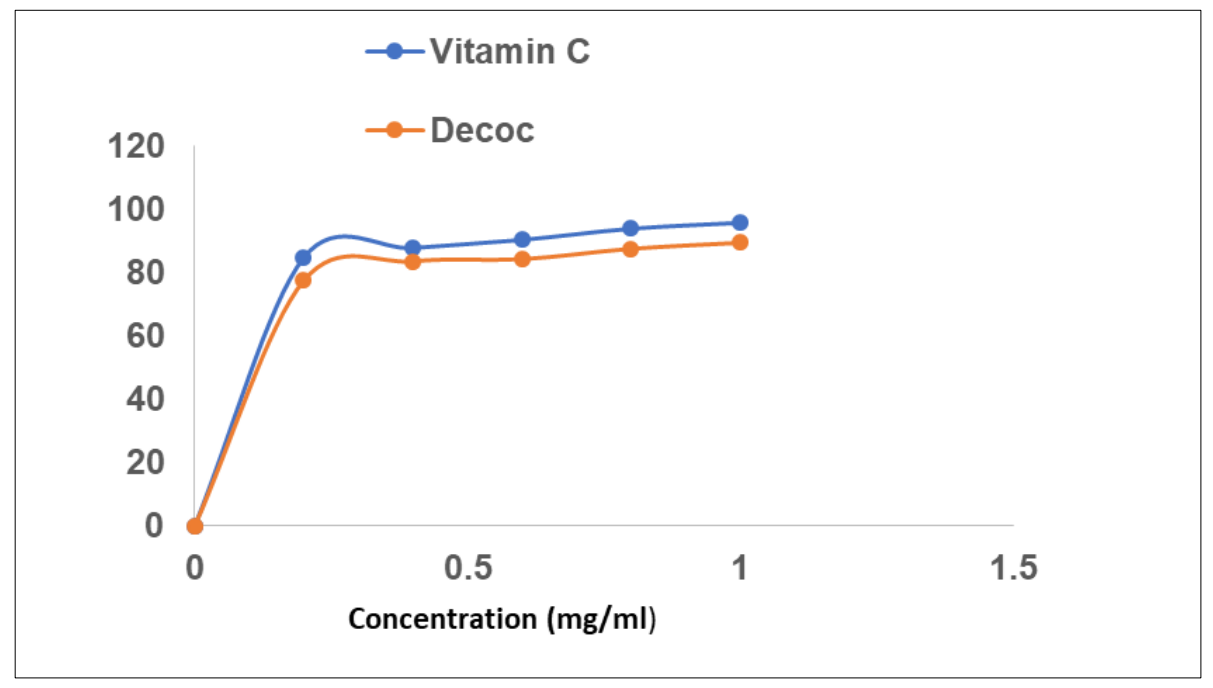

Figure 1 Curve showing the percentage inhibition of Sclerocarya birrea decoction and Vitamin C

Table 1 Percentage inhibition (\%) and IC50 (mg/ml)

\begin{tabular}{|l|c|c|c|}
\hline Decoction and reference compound & Percentage of Inhibition (\%) & IC50 (mg/ml) & $\mathbf{( R}^{\mathbf{2}} \mathbf{~}$ \\
\hline Vitamin C & $95,78 \pm 0,00$ & 6,52 & 0,95 \\
\hline Decoction of S. birrea & $89,46 \pm 0,02$ & 5,51 & 0,96 \\
\hline
\end{tabular}

\subsection{Effects of Sclerocarya birrea root bark aqueous extracts on behavioral parameters in the T- maze test}

3.2.1. Effects of Sclerocarya birrea root bark aqueous extracts on the preferred arm enter latency, Time spent in the discriminated arm and Number of returns to the starting arm.

Administration of Sclerocarya birrea aqueous extracts to mice significantly decreased during habituation, the preferred arm choice latency (fig. $2 \mathrm{~A}$ ) $[\mathrm{F}(5,24)=23.25 ; \mathrm{P}<0.001]$ ranging from $19 \pm 1 \mathrm{sec}$ for the negative control group to $7 \pm$ $1.4 ; 3.4 \pm 1.5$ and $2.8 \pm 0$ sec for $102.5 ; 205$ and $410 \mathrm{mg} / \mathrm{kg}$ doses of decoction respectively. Similarly, during acquisition 
the latency also decrease, from $16 \pm 2 \mathrm{sec}$ for the negative control group to $6.6 \pm 1.5 ; 2.8 \pm 0.5$ and $2.4 \pm 0.5 \mathrm{sec}$ for 102.5 ; 205 and $410 \mathrm{mg} / \mathrm{kg}$ dose of the decoction respectively $[\mathrm{F}(5,24)=24.10 ; \mathrm{P}<0.001]$. During retention, this number continues to decrease varying from $12.4 \pm 0.5 \mathrm{sec}$ for the negative control group to $5 \pm 1.5 ; 2.2 \pm 0.5$ and $1.8 \pm 0$ sec for $102.5 ; 205$ and $410 \mathrm{mg} / \mathrm{kg}$ doses of the decoction respectively $[\mathrm{F}(5,24)=38 ; \mathrm{P}<0.001]$.

During probe test or retention, it also appears a reduction of the number of returns to the starting arm (Figure 2B) varying from $14.4 \pm 2$ for the negative control group to $3.8 \pm 1.5 ; 1.4 \pm 0.5$ and $1.6 \pm 1$ for $102.5 ; 205$ and $410 \mathrm{mg} / \mathrm{kg}$ doses of the decoction respectively $[\mathrm{F}(5,24)=61.92 ; \mathrm{P}<0.001]$. Concerning the time spent in discriminated arm, it also appear a reduction(Figure $2 \mathrm{C}$ ) from $199 \pm 1 \mathrm{sec}$ for the negative control group to $47 \pm 5.5 ; 20 \pm 2$ and $29.4 \pm 3 \mathrm{sec}$ corresponding to the $102.5 ; 205$ and $410 \mathrm{mg} / \mathrm{kg}$ doses of the plant respectively $[\mathrm{F}(5,24)=116.6 ; \mathrm{P}<0.001]$.

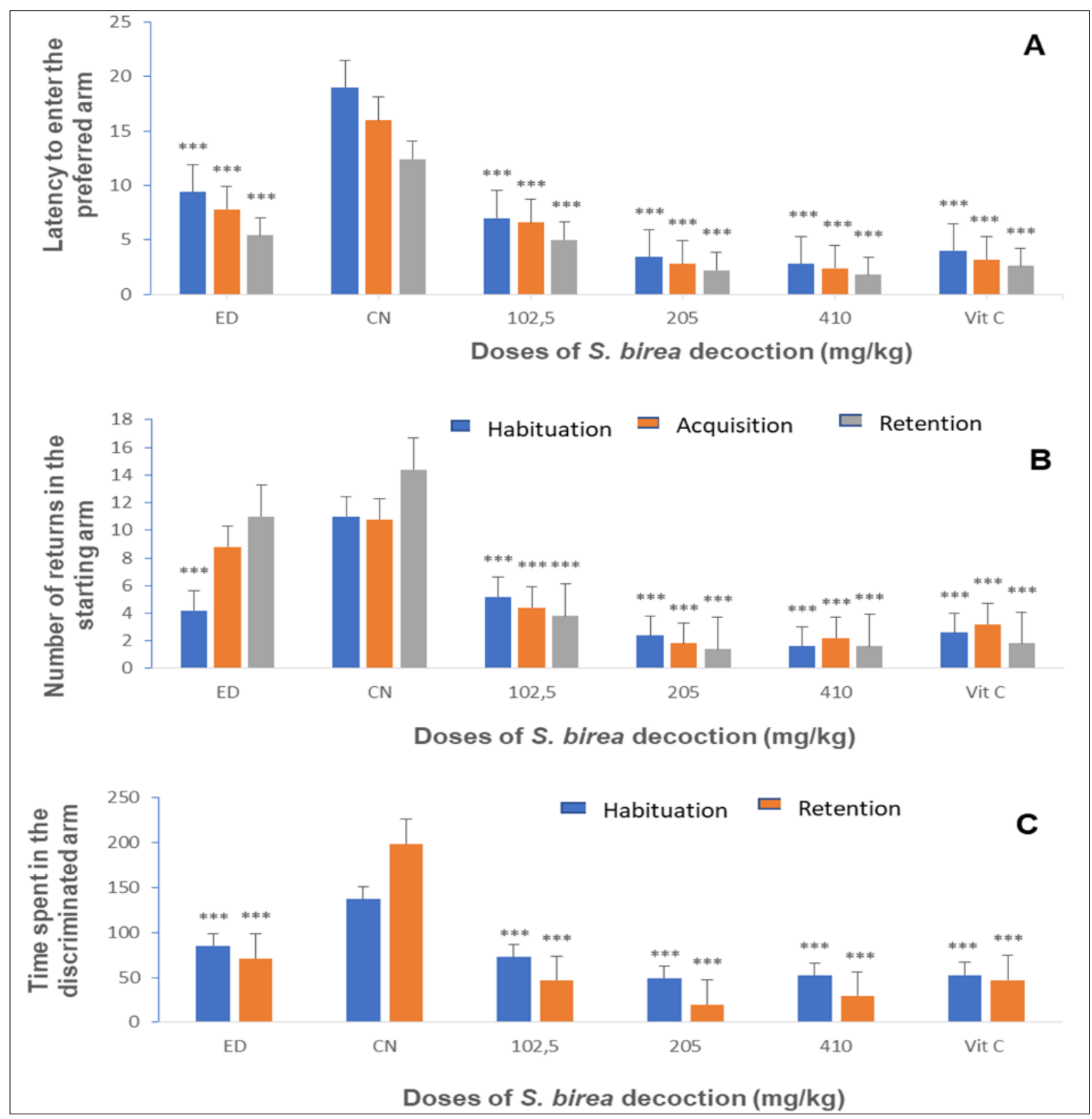

Figure 2 Effects of Sclerocarya birrea root bark aqueous extracts on the preferred arm enter latency, Time spent in the discriminated arm and Number of returns to the starting arm on the T-maze

(A) Latency to enter the preferred arm. (B) Number of returns to the starting arm. (C) Time spent in the discriminated arm. Each bar represents the mean $\pm S E M ; n=5,{ }^{* * *} \mathrm{p} \leq 0.001$, significant difference from the negative control that received monosodium glutamate. $\mathrm{ED}=$ distilled water (normal control), $\mathrm{CN}=$ negative control (treated only with monosodium glutamate at $4 \mathrm{mg} / \mathrm{kg}$ ) and VIT C = vitamin C at $100 \mathrm{mg} / \mathrm{kg}$ (positive control), S. birea = Sclerocarya birrea . 
3.2.2. Effects of Sclerocarya birrea root bark aqueous extracts on time spent in the preferred arm, number of entries in the preferred arm and number of entries in the discriminated arm on the T-maze.

It also appears that the administration of Sclerocarya birrea aqueous extracts to mice significantly increased during retention the time spent in the preferred arm (Figure 3A) ranging from $49 \pm 1.5 \mathrm{sec}$ for the negative control group to $167.4 \pm 2.5$ and $203.6 \pm 2.5 \mathrm{sec}$ for the 205 and $410 \mathrm{mg} / \mathrm{kg}$ doses of the decoction $[\mathrm{F}(5,24)=37.28$; $\mathrm{P}<0.001]$. similarly, Sclerocarya birrea decoction significantly increased the number of entries in the preferred arm (Figure 3B) going from $4.2 \pm 0.5$ for the negative control group to $40.6 \pm 16 ; 33.4 \pm 3.5$ and $20.4 \pm 0.5$ corresponding to $102.5 ; 205$ and 410 $\mathrm{mg} / \mathrm{kg}$ of decoction respectively $[\mathrm{F}(5,24)=24.76 ; \mathrm{P}<0.001]$.

Dissimilarly, Sclerocarya birrea decoction significantly reduced the number of entries in the discriminated arm (Figure 3C) varying from $16.6 \pm 0.5$ for the $C N$ group to $4.4 \pm 0.5 ; 1.6 \pm 0$ and $2.4 \pm 0.5$ corresponding to $102.5 ; 205$ and 410 $\mathrm{mg} / \mathrm{kg}$ of decoction respectively $[\mathrm{F}(5,24)=16.66 ; \mathrm{P}<0.001]$.

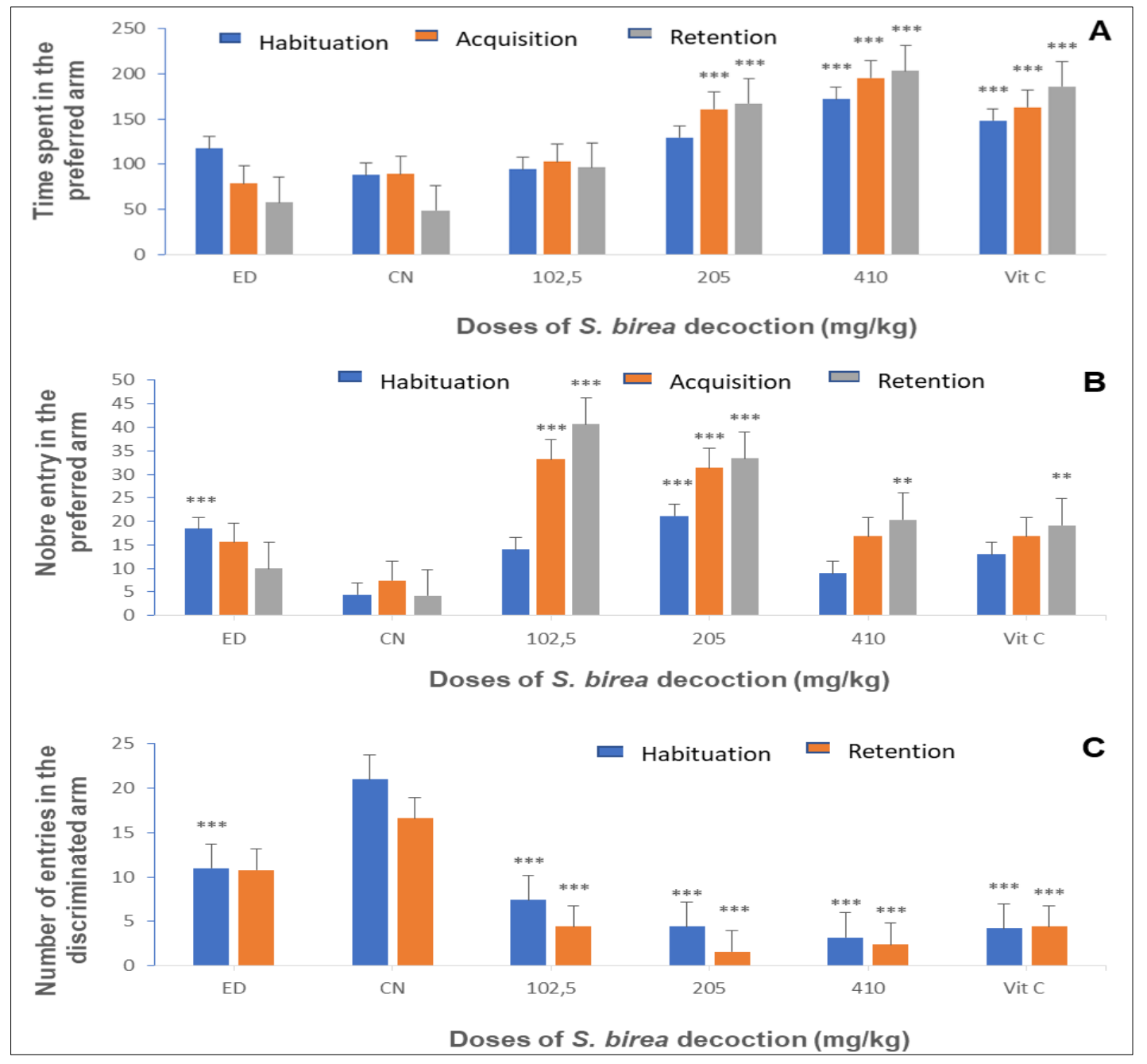

Figure 3 Effects of Sclerocarya birrea root bark aqueous extracts on time spent in the preferred arm, number of entries in the preferred arm and number of entries in the discriminated arm on the T-maze

(A) Time spent in the preferred arm. (B) Number of entries in the preferred arm. (C) Number of entries in the discriminated arm. Each bar represents the mean \pm SEM; $n=5,{ }^{* *} p \leq 0.01, * * * p \leq 0.001$, significant difference from the negative control that received monosodium glutamate. $\mathrm{ED}=$ distilled water (normal control), $\mathrm{CN}=$ negative control (treated only with monosodium glutamate at $4 \mathrm{mg} / \mathrm{kg}$ ) and VIT C = vitamin C at $100 \mathrm{mg} / \mathrm{kg}$ (positive control), S. birea = Sclerocarya birrea. 


\subsection{Effects of Sclerocarya birrea root bark aqueous extracts on the latency time to discover object $A$ and $B$, Time spent with objects $A$ and $B$, Number of visits to objects $A$ and $B$ and Percentage of the Recognition Index in the object recognition in an open field}

Interestingly, like vitamin C, Sclerocarya birrea daily treatment of animals significantly reduced the latency to discover the new object B (Figure 4A) which varied from $5.4 \pm 1.12 \mathrm{sec}$ for the negative control group to $2.2 \pm 0.64 ; 1.6 \pm 0.72$ and $2 \pm 0.40 \mathrm{sec}$ corresponding to $102.5 ; 205$ and $410 \mathrm{mg} / \mathrm{kg}$ doses of the decoction, respectively and 1,40 \pm 0.46 for vitamin $C[F(5,24)=14.30 ; \mathrm{P}<0.001]$. Similarly, Sclerocarya birrea decoction significantly reduced the latency to discover the familiar object A (Figure $4 \mathrm{~A}$ ) from $6.4 \pm 0.88 \mathrm{sec}$ for the negative control group to $3.4 \pm 0.88 ; 1.8 \pm 0.64$ and $2.8 \pm 0.64 \mathrm{sec}$ corresponding to $102.5 ; 205$ and $410 \mathrm{mg} / \mathrm{kg}$ of the decoction, respectively $[\mathrm{F}(5,24)=16.70 ; \mathrm{P}<0.001]$.

In contrast, Sclerocarya birrea decoction significantly increased the exploration frequencies of the new object B (Figure 4B) from $1.8 \pm 0.64$ for the negative control group to $6.8 \pm 1.44 ; 9.8 \pm 1.36$ and $11.2 \pm 1.44$ corresponding to $102.5 ; 205$ and $410 \mathrm{mg} / \mathrm{kg}$ of the decoction, respectively $[\mathrm{F}(5,24)=22.84 ; \mathrm{P}<0.001]$. It appears from this figure a significant reduction of the exploration frequencies in familiar object A (Figure 4B) ranging from $11.4 \pm 12.58$ for the negative control group to $6.6 \pm 0.88 ; 4.2 \pm 1.82$ and $1.6 \pm 0.48$ corresponding to $102.5 ; 205$ and $410 \mathrm{mg} / \mathrm{kg}$ of the decoction, respectively $[\mathrm{F}(5,24)=24.08 ; \mathrm{P}<0.001]$.

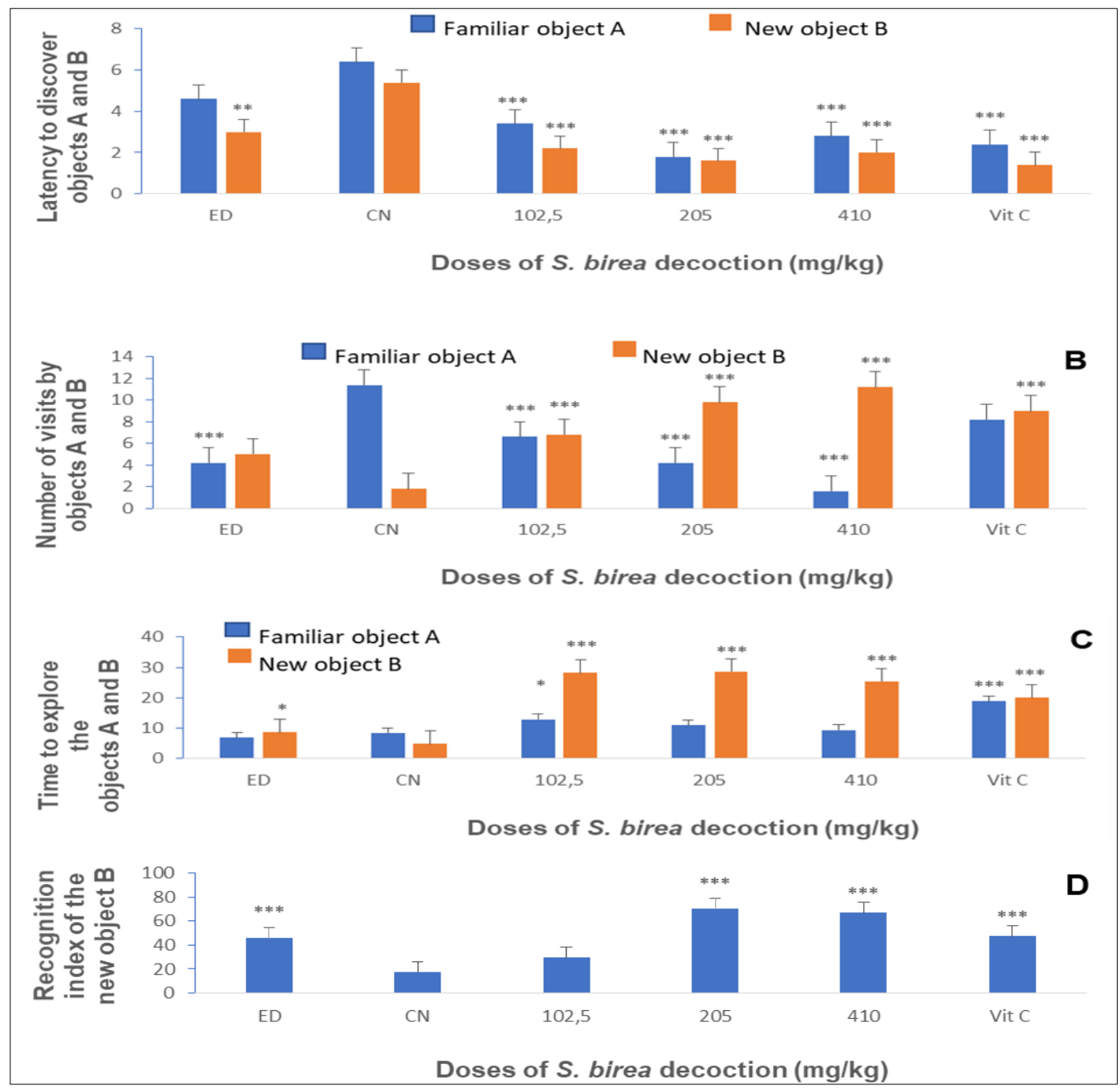

Figure 4 Effects of Sclerocarya birrea root bark aqueous extracts on the latency time to discover object A and B, Time spent with objects A and B, Number of visits to objects A and B and Percentage of the Recognition Index in the object recognition on an open field

Sclerocarya birrea decoction also significantly increased the exploration time of object B (Figure 4C) from $4.8 \pm 1.36 \mathrm{sec}$ for the negative control group to $28.2 \pm 1.04 ; 28.6 \pm 1.52$ and $25.4 \pm 0.88 \mathrm{sec}$ corresponding to $102.5 ; 205 \mathrm{and} 410 \mathrm{mg} / \mathrm{kg}$ of the decoction, respectively $[\mathrm{F}(5,24)=183.2 ; \mathrm{P}<0.001]$. Similarly, the plant extract decoction increased the 
exploration time of object A (Figure 4C) from $8.4 \pm 1.28 \mathrm{sec}$ for the negative control group to $12.8 \pm 1.44 \mathrm{sec}$ for the $102.5 \mathrm{mg} / \mathrm{kg}$ dose of the decoction $[\mathrm{F}(5,24)=21.62 ; \mathrm{P}<0.001]$. The different doses of Sclerocarya birrea decoction significantly increased the recognition index of the new object B (Figure 4D), ranging from $17.68 \pm 1.77$ in negative control group mice to $70.3 \pm 5.36$ and $66.96 \pm 4.72$ in those treated with 205 .

(A) Latency time to discover object A and B. (B) Number of visits to objects A and B. (C) Time spent with objects A and B. (D) Percentage of the Recognition Index of the novel object. Each bar represents the mean \pm SEM; $n=5$, * $p \leq 0.05$, ** $\mathrm{p} \leq 0.01,{ }^{* * *} \mathrm{p} \leq 0.001$, significant difference from the negative control that received monosodium glutamate. ED $=$ distilled water (normal control), $\mathrm{CN}=$ negative control (treated only with monosodium glutamate at $4 \mathrm{mg} / \mathrm{kg}$ ) and VIT $\mathrm{C}=$ vitamin $\mathrm{C}$ at $100 \mathrm{mg} / \mathrm{kg}$ (positive control), S. birea = Sclerocarya birrea.

\subsection{Effects of Sclerocarya birrea root bark aqueous extracts on super oxide dismutase and catalase activities, and in reduced glutathione and malondialdehyde levels in the brain of monosodium glutamate treated mice}

As present in table 2, exposure of animals to MSG for 15 days significantly increased the concentration of MDA and significantly reduced the amount of CAT, GR and SOD in the negative control group compared to the normal control. However, Sclerocarya birrea decoction significantly antagonized the oxidative damage induced by MSG by reducing the levels of MDA and increasing the concentration of CAT, GR, SOD compared to negative control and normal respectively $[F(5,24)=755.8 ; \mathrm{P}<0.001] ;[\mathrm{F}(5,24)=7.921 ; \mathrm{P}<0.001] ;[\mathrm{F}(5,24)=105.8 ; \mathrm{P}<0.001]$ and $[\mathrm{F}(5,24)=4.667 ; \mathrm{P}<0.004]$.

Table 2 Effects of Sclerocarya birrea root bark aqueous extracts on super oxide dismutase and catalase activities, and in reduced glutathione and malondialdehyde levels in the brain of monosodium glutamate treated mice

\begin{tabular}{|l|c|l|l|c|}
\hline treatment15 days & MDA & CAT & GR & SOD \\
\hline ED & $4.95 \pm 0.027^{* * *}$ & $13.55 \pm 0.50^{* *}$ & $0.06 \pm 0.00^{* * *}$ & $4.48 \pm 0.15$ \\
\hline ED + MSG & $10.62 \pm 0.14$ & $10.73 \pm 0.37$ & $0.03 \pm 0.00$ & $4.07 \pm 0.48$ \\
\hline $102.5+$ MSG & $8.56 \pm 0.10^{\mathrm{a} * * *}$ & $13.80 \pm 0.42^{* *}$ & $0.05 \pm 0.00^{\mathrm{a} * * *}$ & $5.15 \pm 0.34^{* *}$ \\
\hline $205+$ MSG & $9.81 \pm 0.15^{\mathrm{a} * *}$ & $11.83 \pm 0.57$ & $0.06 \pm 0.00^{* * *}$ & $4.76 \pm 0.36$ \\
\hline $410+$ MSG & $10.75 \pm 0.17^{\mathrm{a}}$ & $11.39 \pm 0.37^{\mathrm{c}}$ & $0.03 \pm 0.00^{\mathrm{a}}$ & $4.86 \pm 0.20$ \\
\hline VIT C + MSG & $5.12 \pm 0.19^{\mathrm{a} * * *}$ & $13.92 \pm 1.39^{* *}$ & $0.07 \pm 0.00^{\mathrm{*} * *}$ & $5.16 \pm 0.08^{* *}$ \\
\hline
\end{tabular}

Each value represents the mean $\pm S E M ; n=5 . * * p \leq 0.01$, ${ }^{* * *} p \leq 0.001$, significant difference from $C N$. $c p \leq 0.05, b p \leq 0.01$, ap $\leq 0.001$ significant difference from normal control (ED), $\mathrm{ED}=$ distilled water (normal control), $\mathrm{CN}=$ negative control (monosodium glutamate), VIT C $=$ vitamin C $(100$ $\mathrm{mg} / \mathrm{kg}$ ), $\mathrm{MSG}=$ monosodium glutamate, $\mathrm{MDA}=$ malondialdehyde, $\mathrm{CAT}$ = catalase, $\mathrm{GR}=$ glutathione reductase, and SOD = superoxide dismutase .

\section{Discussion}

The mnemonic and neuroprotective effect of Sclerocarya birrea root bark decoction was determined in this study. From the analysis, it was found that the decoction of Sclerocarya birrea root barks has a percentage of inhibition of $89.46 \pm$ 0.02 and the IC50 value is about $5.51 \mathrm{mg} / \mathrm{mL}$, significantly lower than those of vitamin C with the percentage of inhibition of $95.78 \pm 0.00$ and the IC50 is about $6.52 \mathrm{mg} / \mathrm{mL}$. This indicates that Sclerocarya birrea decoction has a very high antiradical activity compared to vitamin $C$ with a very low IC50 value suggesting the massive presence of phenolic compounds in the decoction. These results are similar to those obtained by Koto-te-Nyiwa [31] who stated that the antioxidant power of plant extracts is related to the presence of phenolic compounds. Similarly, Sclerocarya birrea decoction significantly decreased the latency of choosing the preferred arm and the number of return to the starting arm indicate the increase in cognitive performance [32], the number of return to the starting arm suggests the exploration and protection of memory [33]. Varying the number and time spent in the preferred and discriminated arm elicits improved memory as well as increased exploration [34]. We observed a decrease in latency to find object B compared to object A during the object recognition test. The number and duration of exploration of object $B$ is higher than that of object A, indicating the natural tendency of rodents to explore a novel object more compared to a familiar object [35]. Recognition of the novel object was significantly higher in mice given the decoction and vitamin C compared to those in the CN group. These results show that the decoction of Sclerocarya birrea root barks has memetic and neuroprotective effects that involve short-term memory processes, verifying the recognition of the new object compared to the familiar object [36]. These results corroborate those of Chemero and Heyser who had shown that ethanol increases exploration of the new object relative to the familiar object [37]. 
Glutamate is the most important excitatory neurotransmitter in the mammalian brain. However, deregulation of glutamatergic neurotransmission leads to neurodegeneration, neurotoxicity and oxidative stress damage in the brain [3].

The determination of oxidative stress markers in this study shows that MSG significantly increases the concentration of MDA, and reduces the activity of CAT, GR and SOD in the brain of mice, suggesting an increase in oxidative stress. Oxidative stress is caused by the accumulation of reactive oxygen species in cells or their incomplete degradation. Thus, the prolonged treatment of animals with MSG generates the massive destruction of neuronal cells by the accumulation of reactive oxygen species, leading to memory loss [38]. On the other hand, administration of Sclerocarya birrea root bark decoction inhibits the action of MSG, significantly increases the concentration of GR, SOD, CAT activity and decreases the concentration of MDA resulting in a significant reduction of oxidative stress and thus an increase in learning capacity and memory. Furthermore, the reduction of stress improves the proper functioning of memory [33]. Hence we can affirm that the decoction of Sclerocarya birrea root bark inhibits the effects of oxidative stress while boosting learning and memory capacities.

\section{Conclusion}

In sum, the present work allowed us to find that the decoction of Sclerocarya birrea root barks has the inhibitory power on MSG. These results show that the decoction of Sclerocarya birrea root barks has antioxidant and neuroprotective properties, justifying its use in traditional medicine in the treatment of neurodegenerative diseases such as Alzheimer's, Parkinson's and memory disorders. For a better understanding of the neuroprotective effects of S. birrea, it would be wise to consider further studies that could identify and characterize its active ingredients and their mechanism of action.

\section{Compliance with ethical standards}

\section{Acknowledgments}

The authors are very thankful to Laboratory of medicinal plants, health and galenic formulation, University of Ngaoundere, Cameroon, for supporting us by providing apparatus and drugs.

\section{Disclosure of conflict of interest}

The authors declare that they have no conflict of interest.

\section{Statement of ethical approval}

The protocols were performed in concordance with the International Guide for the Care and Use of Laboratory Animal (National Institute of Health; publication No. 85-23, revised 1996) and the Cameroon National Ethical Committee, Yaoundé (No. FW-IRB00001954)

\section{References}

[1] Pinel J. Biopsychologie - Pearson Education France. 2007 ; 508.

[2] AV Swamy, NL Patel, PC Gadad, BC Koti, UM Patel, AHM Thippeswamy, DV Manjula. Neuroprotective activity of pongamia pinnata in monosodium glutamate-induced neurotoxicity in rats. Indian journal of pharmaceutical sciences. 2013; 75(6): $657-663$.

[3] BD Shivasharan, P Nagakannan, BS Thippeswamy, VP Veerapur. Protective effect of Calendula officinalis L. flowers against monosodium glutamate induced oxidative stress and excitotoxic brain damage in rat. Indian Journal of Clinical Biochemistry. 2013; 28(3): 292 - 298.

[4] Hassan ZA, Arafa MH, Soliman WI, Atteia HH, Al-Saeed HF. The effects of monosodium glutamate on thymic and splenic immune functions and the role of recovery (biochemical and histological study). Journal of cytology and histology. 2014; 5(6).

[5] Farombi EO, Onyema 00. Monosodium Glutamate Induced Oxidative Damage and Genotoxicity in the Rat: Modulatory Role of Vitamin C, Vitamin E and Quercetin. Human Experimental Toxicology. 2006; 25(5): 251 - 259.

[6] World Health Organization, WHO Strategy on Traditional Medicine; World Health Organization; Geneva. 2008; 65. 
[7] Ngo Bum E, Taiwe GS, Moto FC, Ngoupaye GT, Vougat RN, Sakoue VD, Gwa C, Ayissi ER, Dong C, Rakotonirina A. Rakotonirina. "Antiepileptic traditional medicine to treat epilepsy." In Clinical and genetic aspects of epilepsy. InTech. 2011.

[8] Moto FC, Tanyi Mbafor J, Ngo Bum E, Kouémou N, Kavaye Kandeda A, Talla E, Dimo T, Rakotonirina A, Rakotonirina SV. Evaluation of the sedative and anticonvulsant properties of three Cameroonian plants. Africa Journal of Traditional; Complementary and Alternative medicines. 2011; 8(5s): 181-190.

[9] Somboro AA, Patel K, Diallo D, Sidibe L, Chalchat JC, Figueredo G, Ducki S, Troin Y, Chalard P. An ethnobotanical and phytochemical study of the African medicinal plant Guiera senegalensis J.F Gmel. Journal of Medicinal Plants Research. 2011; 5(9): 1639-1651.

[10] Ojewole JA. Evaluation of the analgesic, anti-inflammatory and anti-diabetic properties of Sclerocarya birrea (A. Rich) Hochst. Stem-bark aqueous extract in mice and rats. Phytother Res. 2004; 18(8): 601-608.

[11] Glew RS, VanderJagt DJ, Huang YS, Chuang L-T, Bosse R, Glew RH. Nutritional analysis of the edible pit of Sclerocarya birrea (A.Rich). Hochst. In the Republic of Niger (daniya, haussa), in journal of Food Composition and Analysis 17, Edition Elsevier, USA. 2004; 99-111.

[12] Ngo Bum E, Dawack DL, Schmutz M, Rakotonirina A, Rakotonirina SV, Portet C, Jeker A, Olpe HR, Herrling P. Anticonvulsant activity of Mimosa pudica decoction. Fitoterapia. 2004; 75: 310-315.

[13] Boubekri C. Study of the antioxidant activity of polyphenols extracted from Solanun melongena by electrochemical techniques. PhD thesis, Mohamed Khider-Biskra University, Algeria. 2014; 210.

[14] Moreno SC. Method used to evaluate the free radical scavenging activity in food and biological systems. Food Science and Technology International. 2002; 8(3): 121-137.

[15] Nana O, Momeni J, Boyom FF, Ngassoum MB. Influence of microwave assisted extraction on antioxidant and antiplasmodial activities of Trichilia roka extracts. The Journal of Phytopharmacology. 2015; 4(5): $248-252$.

[16] Talla E, Nyemb NJ, Tchinda AT, Zambou SGD, Biyanzi, Sophie L, Vander LE, Mbafor TJ. Antioxidant activity and a new ursane-type triterpene from Vitellaria paradoxa (Sapotaceae) stem barks. European Journal of Medicinal Plants. 2016; 16(3): 1-20.

[17] Percie du, Sert N, Hurst V, Ahluwalia A, Alam S, Avey MT, Baker M, et al. The ARRIVE guidelines 2.0: Updated guidelines for reporting animal research. Journal of Cerebral Blood Flow \& Metabolism. 2020; 40(9): $1769-77$.

[18] Organization WH. General guidelines for methodologies on research and evaluation of traditional medicine. World Health Organization. 2000.

[19] Geha RS, Beiser A, Ren C, Patterson R, Greenberger PA, Grammer LC, Ditto AM, Harris KE, Shaughnessy MA, Yarnold PR, Corren J, Saxon A. Multicenter, double-blind, placebo-controlled, multiple-challenge evaluation of reported reactions to monosodium glutamate. J Allergy Clin Immunol. 2000; 106(5): 973-980.

[20] Deacon, JNP Rawlins. T-maze alternation in the rodent. Nature Protocols. 2006; 1(1): 7 - 12.

[21] Jenck F, Moreau JL, James RM, Gavin JK, Rainer KR, Monsma FJ, Nothatker HP, Civelli O, Orphanin FQ. acts as an anxiolytic to attenuate behavioral responses to stress. Proceedings of the National Academy of Sciences of the United States of America. 1997. 94(7): 14854-14858.

[22] Ennaceur, J Delacour. A new one-trial test for neurobiological studies of memory in rats, Behavioral data. Behavioural brain research. 1988; 31(1): 47 - 59.17.

[23] Antunes M, Biala G. The novel object recognition memory: neurobiology, test procedure, and its modifications. Cognitive processing. 2012; 13(2): 93 -110.

[24] Oliveira AM, Hawk JD, Abel T, Havekes R. Post-training reversible inactivation of the hippocampus enhances novel object recognition memory, Learning \& memory. 2010; 17(3): 155 - 160.

[25] Ennaceur A. One-trial object recognition in rats and mice: methodological and theoretical issues, Behavioural brain research. 2010; 215(2): $244-254$.

[26] R Rajendran, DB Ambikar, RA Khandare, VD Sannapuri, NS Vyawahare, P Clayton. Nootropic Activity of Caralluma fimbriata Extract in Mice. Food and Nutrition Sciences. 2014; 5(2): 147 - 152.

[27] Koutseff Alexis, Action study between chronic stress and apoliprotein E polymorphism in emotional and cognitive processes in mice: implication in Alzheimer's disease. Institute of Molecular and Cellular Biology. 2011 ; 35: 1-35. 
[28] Oyanagui, Y, Réévaluation des méthodes de dosage et mise en place du kit pour superoxyde dismutase activity. Activité de superoxyde dismutase. Anal. Anal. Biochem. Biochem, 1984. 142, 290-296.142, 290-296.

[29] Aebi, H, Catalase in vitro. Methods Enzymol. 1984; 105: 121-126.

[30] Mizumo Y, Ohta K. Regional distributions of thiobarbituric acid reactive products, activities of enzymes regulating the metabolism of oxygen free radicals, and some of the related enzymes in adult and aged rat brain. J. Neurochem. 1986; 46: 1344-1352.

[31] Nourooz - Zadeh J, Tajaddidi - Sarmadi J, Lingkle, Wolff SP. Low density lipoprotein is the major carrier of lipid hydroperoxides in plasma. Biochem. 1996; 313: 781-786.

[32] Koto-te-Nyiwa N, Mubindukila REN, Mpiana PT, Masengo CA, Robijaona B, Fatiany PR, Takoy L, Ekutsu GE, Zoawe BG. In vitro assessment of antibacterial and antioxidant activities of a Congolese medicinal plant species Anthocleista schweinfurthii Gilg (Gentianaceae). Journal of Modern Drug Discovery and Drug Delivery Research. 2014; 6: 2348-3776.

[33] A Farshchi, G Ghiasi, S Farshchi, MP Khatabi. Effects of Boswellia Papyrifera Gum Extract on Learning and Memory in Mice and Rats. Iranian Journal of Basic Medical Sciences. 2010; 13(2): 9 - 15.

[34] Ennaceur A. Effects of lesions of the substantia in nominata/ventral pallidum, globus pallidus and medial septum on rat's performance in object-recognition and radial-maze tasks: physostigmine and amphetamine treatments. Pharmacological Research. 1998; 38: 251-63.

[35] Sahay A, Scobie K, Hill A, O'carroll C, Kheirbek M, Burghardt N, Fenton A, Dranovsky A \& R. Hen, Increasing adult hippocampal neurogenesis is sufficient to improve pattern separation. Nature, 2011, 472 (7344), 466 - 470.

[36] Chemero A \& Heyser C. Object exploration and a problem with reductionism. Synthese, 2005, 147(5), 403 - 423.

[37] Danysz W. \& Parsons CG, Alzheimer's disease, $\beta$-amyloid, glutamate, NMDA receptors and memantine-searching for the connections, British journal of pharmacology, 2012, 167 (2), 324 - 352.

[38] Kruk-Slomka M, Boguszewska-Czubara A, Slomka T, Budzynska B \& Biala G. Correlations between the memoryrelated behavior and the level of oxidative stress biomarkers in the mice brain, provoked by an acute administration of CB receptor ligands. Neural plasticity, 2016. 